University of Nebraska - Lincoln

DigitalCommons@University of Nebraska - Lincoln

Faculty Papers and Publications in Animal

Science

Animal Science Department

December 2003

\title{
The National Pork Producers Council Maternal Line National \\ Genetic Evaluation Program: A comparison of six maternal genetic lines for female productivity measures over four parities
}

\author{
J. S. Moeller \\ Ohio State University \\ R. K. Johnson \\ University of Nebraska-Lincoln, rjohnson5@unl.edu \\ J. W. Mabry \\ lowa State University \\ T. J. Baas \\ lowa State University \\ O. W. Robison \\ North Carolina State University, Raleigh
}

Follow this and additional works at: https://digitalcommons.unl.edu/animalscifacpub

Part of the Animal Sciences Commons

Moeller, J. S.; Johnson, R. K.; Mabry, J. W.; Baas, T. J.; and Robison, O. W., "The National Pork Producers Council Maternal Line National Genetic Evaluation Program: A comparison of six maternal genetic lines for female productivity measures over four parities" (2003). Faculty Papers and Publications in Animal Science. 66.

https://digitalcommons.unl.edu/animalscifacpub/66

This Article is brought to you for free and open access by the Animal Science Department at DigitalCommons@University of Nebraska - Lincoln. It has been accepted for inclusion in Faculty Papers and Publications in Animal Science by an authorized administrator of DigitalCommons@University of Nebraska - Lincoln. 


\title{
The National Pork Producers Council Maternal Line National Genetic Evaluation Program: A comparison of six maternal genetic lines for female productivity measures over four parities ${ }^{1}$
}

\author{
S. J. Moeller ${ }^{2 *}$, R. N. Goodwin $\dagger$, R. K. Johnson \\ *Department of Animal Sciences, The Ohio State University, Columbus 43210; $\uparrow$ National Pork Board, \\ Des Moines, IA 50325; $\$$ Department of Animal Science, University of Nebraska, Lincoln 68583; \\ $\S$ Department of Animal Science, Iowa State University, Ames 50011; and \\ IINorth Carolina State University, Raleigh 27695
}

\begin{abstract}
Litter $(\mathrm{n}=8,424)$ and female performance records were collected in two breed-to-wean production units in order to evaluate genetic line differences for sow longevity and maternal performance over four parities. Lines evaluated were American Diamond Genetics, Danbred North America, Dekalb-Monsanto DK44, Dekalb-Monsanto GPK347, Newsham Hybrids, and National Swine Registry. Females within a line were derived from a minimum of 65 sires, 197 dams (three dams per sire), and a maximum of three daughters per dam, except in the GPK347, which were produced using semen from 12 Nebraska Index boars mated with Dekalb-Monsanto Line 34 females. All lines expressed 100\% maternal heterosis. Mixed model statistical procedures were used with fixed effects including genetic line, parity, production unit, and two-way interactions. Random effects included a contemporary week of production and female for repeated records. Lactation length (average $15 \mathrm{~d}$ ) was included as a linear covariate where appropriate. In total, 3,599 females entered as early-weaned pigs, 3,283 entered the breeding herd, 2,592 farrowed at least a single litter, and 1,656 and completed four parities. Line $(P<0.001)$ and
\end{abstract}

parity $(P<0.001)$ effects were observed for virtually all traits measured. Ranges of genetic line differences averaged across parities were 1.76 pigs for total born, 1.45 pigs born alive, and 0.31 stillborn pigs per litter. Ranges of line differences in total and live litter weight were 1.4 and $1.3 \mathrm{~kg}$, respectively. Ranges among lines, within Parities 1 through 4, for litter size at weaning were $0.56,1.08,0.91$, and 0.64 pigs per litter, respectively. Line differences for weight $(33.8 \mathrm{~kg})$ and backfat depth $(6.4 \mathrm{~mm})$ at farrowing, lactation feed intake $(8.7$ $\mathrm{kg})$, weight loss $(5.0 \mathrm{~kg})$, and backfat loss $(0.87 \mathrm{~mm})$ were observed. Extended wean-to-estrus interval was related to variation in weight, feed intake, and backfat loss in all lines except the GPK347. The GPK347 females farrowed and weaned the largest number of pigs, ate less feed in lactation, and lost more backfat and weight during lactation, yet they had the largest litters and the shortest wean-to-estrus intervals. Line $\times$ parity interactions existed for many traits due to small rank changes, but in general, the high- and low-ranked lines did not change. Genetic line differences in reproductive efficiency through four parities exist and must be recognized when choosing a female line.

Key Words: Fertility, Genetic Variation, Litter Traits, Pigs

(C2004 American Society of Animal Science. All rights reserved.

J. Anim. Sci. 2004. 82:41-53

\section{Introduction}

Breeding herd productivity is a primary factor that determines pork industry profitability. Large litters of

\footnotetext{
${ }^{1}$ Funding for the project was provided through producer check-off monies of the National Pork Board and administered by the National Pork Producers Council.

${ }^{2}$ Correspondence: 122 Animal Science Bldg., 2029 Fyffe Rd. (phone: 614-688-3686; fax: 614-292-3513; e-mail: moeller.29@osu.edu). Received March 5, 2003.

Accepted September 4, 2003.
}

high-quality piglets from females that breed and rebreed at regular intervals with minimal involuntary culling provide the best opportunity for long-term viability and profitability. Rothschild and Bidanel (1998) summarized heritability estimates for most reproductive traits as being low to moderate and noted that relative variation among breeds is high. Bidanel et al. (1994) and Casey et al. (1994) reported genetic selection for reproductive performance or components of reproductive performance were effective. Genetic trends for reproduction in U.S. purebred Yorkshire (See et al., 2000) and Landrace (Stalder et al., 2000) populations suggest that genetic selection has been effective for 
improving reproductive performance. Commercial females are predominantly $\mathrm{F}_{1}$ crosses among breeds and breeding company lines that were selected for increased reproduction in addition to having been selected for growth and carcass traits. As a result, specialized crossbreeding programs, using maternal and terminal sire lines, are used by most producers. Swine producers have a wide range of maternal lines to choose from; however, very little data comparing maternal performance among genetic lines under standardized environmental conditions are available. Lack of comparative data is due in part to the proprietary nature of seedstock suppliers and the sampling requirements necessary to obtain statistically valid comparisons among genetic lines. The objective of this project was to compare maternal genetic performance among commercially available maternal lines under standard environmental conditions where population sizes were sufficiently large to assess true genetic differences.

\section{Materials and Methods}

\section{Program Description}

The Maternal Line National Genetic Evaluation Program (MLP) was initially conceived in 1990 under the guidance of the National Pork Producers Council (NPPC) Genetic Programs Committee (GPC). The committee comprised scientists from academia and allied industry and producer leaders from throughout the United States. Its charge was to develop a scientifically sound, unbiased genetic evaluation protocol to evaluate maternal lines available in the United States for reproductive performance and female longevity. The MLP was implemented following a vote of the delegates at the 1996 NPPC Pork Forum. The first females entered the trial in January of 1997 and final records on fourthparity females were collected in August of 1999. The GPC and NPPC personnel were responsible for overseeing the data collection procedures and data analysis.

\section{Program Size}

The size of the MLP was based on the number of records per line needed to detect line differences in sow longevity that were equal to or greater than $20 \%$ of the phenotypic standard deviation with power equal to 0.75 and significance rate of 0.05 (NPPC, 2000). Longevity was defined as the number of days from when a female entered the breeding herd until she was removed or until she had weaned her fourth litter, whichever came first. Based upon a heritability estimate of 0.15 , sample size for each line was calculated to be a minimum of 531 sows from 65 sires and 197 dams (three dams per sire) with records of longevity. Gilts entered the experiment after being weaned between 7 and $20 \mathrm{~d}$ of age. Using estimates of industry-reported average wean-tofinish mortality and morbidity along with previous experiences from the NPPC Terminal Line Sire Evalua- tion (NPPC, 1995), where commingled early-weaned pigs were raised through to the finishing stage of production, the GPC assumed that $90 \%$ of females entering the wean-to-finish facilities would enter the breeding herd. Therefore, each line to be tested entered a minimum of 590 weaned gilts with the family distribution as near as could be achieved to the target values.

\section{Definition of Genetic Populations}

A seedstock population was eligible to enter the program if at least $90 \%$ of the litters produced in the last $5 \mathrm{yr}$ had dams that were produced within the population and at least $90 \%$ had sires that were produced within the population. Litters were not required to have both the sire and dam born within the population. For litters produced in the most current year, it was also required that $90 \%$ had dams that were produced within the population and $90 \%$ had sires that were produced within the population. Five-generation pedigrees were used to verify that populations met these criteria.

\section{Genetic Line Sampling}

In April 1996, NPPC invited U.S. seedstock suppliers to nominate genetic lines to enter into the MLP program. Of those nominated, the pure lines or breeds of five seedstock suppliers producing six unique $\mathrm{F}_{1}$ cross females (one supplier produced two types of gilts) met the definition of a population. The suppliers, with the acronym for their product in parentheses, were American Diamond Swine Genetics (ADSG; American Diamond Swine Genetics, Prairie City, IA), Danbred, USA (DB; Danbred North American, Seward, NE), DeKalbMonsanto DK44 (DK; Monsanto Choice Genetics, St. Louis, MO), DeKalb-Monsanto GPK347 (GPK347; Monsanto Choice Genetics), National Swine Registry (NSR; West Lafayette, IN), and Newsham Hybrids, USA (NH; Colorado Springs, CO).

The ADSG, DB, DK, and NH females represented commercially available product lines. Each was an $\mathrm{F}_{1}$ cross of maternal lines selected and developed within each company's genetic program. In most cases, these lines originated from Yorkshire/Large White and Landrace breeds, but may have included other breeds. The NSR female was a Landrace-Yorkshire $\mathrm{F}_{1}$ cross produced from the mating of purebred Landrace sires to purebred Yorkshire females and the reciprocal cross.

The GPK347 was a three-breed cross, produced by mating $F_{1}$ gilts of the Dekalb-Monsanto Genepacker Line 34 sows with boars of an experimental index line developed at the University of Nebraska. The Nebraska Index Line (Neal et al., 1989; Johnson et al., 1999) was a composite population of Large White and Landrace breeds that was closed in 1981 and then selected for increased ovulation rate, embryonic survival, and litter size at birth for 16 generations. The NE line was maintained with 45 to 85 litters by 15 to 20 sires per generation. Sixteen breeding age boars were available, and 
Table 1. Number of gilts per line that entered wean-to-finish facilities within each entry date

\begin{tabular}{lcccr}
\hline \hline & \multicolumn{3}{c}{ Entry date } \\
\cline { 2 - 5 } Genetic line $^{\mathrm{a}}$ & Feb 12, 1997 & March 5, 1997 & April 16, 1997 & Total \\
\hline ADSG & 230 & 180 & 180 & 590 \\
DB & 179 & 139 & 268 & 586 \\
DK & 132 & 189 & 272 & 593 \\
GPK347 & 172 & 241 & 179 & 592 \\
NH & 235 & 178 & 218 & 631 \\
NSR & 261 & 133 & 173 & 567 \\
Total & 1,209 & 1,060 & 1,290 & 3,559 \\
\hline
\end{tabular}

${ }^{\mathrm{a}} \mathrm{ADSG}=$ American Diamond Swine Genetics; DB = Danbred, USA; DK = DeKalb Monsanto DK44; GPK347 = DeKalb Monsanto GPK347; NSR = National Swine Registry; NH = Newsham Hybrids, USA.

semen was collected from 12 of them to produce gilts for this experiment.

\section{Management of Developing Females}

To standardize herd health at a high level, segregated early-weaning practices (NPPC, 2000) were utilized, and gilts of all genetic lines were commingled. Earlyweaned gilts entered new, identically designed weanto-finish facilities at 7 to $20 \mathrm{~d}$ of age. Gilts were collected from genetic suppliers and entered on one of three dates. On arrival, genetic suppliers provided birth date and litter information. Gilts were ear-tagged and weighed, and teat numbers counted by side. Gilts were penned by genetic line and weight with a stocking rate of approximately 25 per pen. Weights at entry ranged from 1.2 to $8.6 \mathrm{~kg}$ and averaged $4.3 \mathrm{~kg}$. The distribution and total number of gilts entered by date and genetic line are listed in Table 1.

Gilts were provided ad libitum access to feed from entry through $180 \mathrm{~d}$ of age. A five-phase dietary program was followed (NPPC, 2000). The dietary formulations (as-fed basis) were as follows: 1) entry to $9 \mathrm{~kg}$, $23 \% \mathrm{CP}, 1.75 \%$ lysine; 2) 9.0 to $13.6 \mathrm{~kg}, 23.0 \% \mathrm{CP}$, $1.50 \%$ lysine diet; 3) 13.6 to $31.8 \mathrm{~kg}$, a corn-soybean meal-based diet, $23.0 \% \mathrm{CP}$ and $1.35 \%$ lysine; 4) 31.8 to $68.2 \mathrm{~kg}$, corn-soybean meal-based diet, $21.3 \% \mathrm{CP}$ and $1.20 \%$ lysine; and 5) $68.2 \mathrm{~kg}$ to $180 \mathrm{~d}$ of age, corn-soybean meal based diet, $15.9 \% \mathrm{CP}$ and $0.80 \%$ lysine. Metabolizable energy levels in the diets were $3,454,3,289$, $3,458,3,399$, and $3,352 \mathrm{kcal} / \mathrm{kg}$, respectively.

At approximately $165 \mathrm{~d}$ of age, the attending veterinarian, unit manager, and the NPPC program manager culled gilts that had external abnormalities or were considered to be unhealthy. A total of 276 out of 3,599 $(7.67 \%)$ of the original gilts died $(4.6 \%)$ or were removed due to umbilical hernias $(1.4 \%)$, injury $(0.5 \%)$, or unthrifty body condition (1.0\%).

At approximately $180 \mathrm{~d}$ of age, gilts were randomly assigned ear-tags containing sensors for electronic classification and randomly allocated within genetic line and entry date to one of two new 1,600-sow breed-towean production units. At the time of allocation, gilts with chronic illness or injury as determined by the veterinarian or extremely low body weight for the gilt's age (over three standard deviations below the genetic line mean live weight) were culled. Ninety-two percent $(\mathrm{n}=3,283)$ of the gilts that were entered were allotted to a breeding facility. Breeding unit personnel were not provided information on genetic lines of gilts.

Gilts were individually managed upon entry to the breed-wean units. A standard, corn-soybean mealbased diet (13.96\% CP, $0.65 \%$ lysine, $3,264 \mathrm{kcal} / \mathrm{kg} \mathrm{ME}$ ) was offered throughout gestation (as-fed basis). Feed was allocated based on size and body condition (NRC, 1998). Gilts were housed in $54-\times 297$-cm gestation stalls. Small gilts, judged to require additional feed, were placed in pens of six and provided ad libitum access to feed until they weighed enough for reduced feed intake. The percentage of small gilts designated for this management practice was similar across genetic lines.

On arrival to the breed-wean unit, gilts were exposed to vasectomized boars to stimulate estrus. Gilts were observed twice daily, and each date that they exhibited the standing estrus response was recorded. Gilts were bred via AI on the second or later estrous cycle if they were $205 \mathrm{~d}$ of age or older. They were inseminated at first detection of standing estrus and $24 \mathrm{~h}$ later. All gilts were inseminated with pooled semen from boars of a standard terminal sire line that resulted in 100\% heterosis in the offspring. Gilts were culled only if they died, failed to show estrus by $300 \mathrm{~d}$ of age, or expressed estrus by $300 \mathrm{~d}$ of age but failed to conceive in a $60-\mathrm{d}$ breeding period.

\section{Gestation Management}

Gilts and sows were managed individually throughout the trial. Weaned sows were provided ad libitum access to feed from weaning through first mating or $d$ 14 after weaning. For all females, feed intake was reduced to $1.8 \mathrm{~kg} / \mathrm{d}$ for $14 \mathrm{~d}$ following mating to enhance embryo implantation. Daily feed allotments between d 15 after mating through farrowing were determined by using National Research Council nutrition models (NRC, 1998) taking into account sow weight at weaning, 
previous lactation weight loss, and desired gestation weight gain. Daily feed of sows that were considered to be either too thin or too fat was adjusted from the standard NRC recommendation to meet the sow's projected needs. Weight of all feed delivered to each sow was recorded. A veterinarian-prescribed vaccination protocol was followed.

Weaned sows were observed for estrus each day following weaning and were mated 12 and $24 \mathrm{~h}$ after first observation of standing estrus. Wean-to-estrus interval was recorded on all females. All matings were accomplished by AI. Mated females were checked daily for estrus throughout gestation to determine pregnancy status and identify returns to estrus. Females that returned to estrus were mated following the same procedures outlined previously.

\section{Farrowing and Weaning Management}

Ultrasonic backfat depth was measured at the last rib location, approximately 5.0 to $7.0 \mathrm{~cm}$ off the dorsal midline, with an A-mode ultrasound device (600 Series, A-scan Plus, Sonic Industries, Ithaca, NY). Sows were weighed and backfat measurements taken on entry and removal from the farrowing facility. Females were placed in a clean farrowing crate within $3 \mathrm{~d}$ of their expected farrowing date. Females were fed to appetite following parturition and daily feed intake was recorded. Lactation diets (as-fed basis) were corn-soybean meal-based (21.2\% CP, $1.20 \%$ lysine, $3,482 \mathrm{kcal} / \mathrm{kg} \mathrm{ME}$ ).

Within $24 \mathrm{~h}$ after farrowing, total number of pigs born (TB), number of pigs born alive (NBA), number of stillborn pigs (SB), number of mummies (MUM), litter birth weight of fully formed pigs (TBWT), and litter birth weight of live pigs (LBWT) were recorded for each litter. Baby pigs were processed within $24 \mathrm{~h}$ of birth. Injectable iron and veterinarian-prescribed antibiotics were administered. Canine teeth were removed and tails docked following prescribed guidelines. Male pigs were castrated at $10 \mathrm{~d}$ of age.

Transferring of pigs among litters occurred within $48 \mathrm{~h}$ of birth. Pigs were transferred among sows both within and among lines. Pigs that were transferred to another sow were notched in their right ear, but otherwise individual pigs were not identified. Pigs were transferred among sows to establish litter uniformity for both number and weight of pigs sows were allowed to nurse, with the goal being to establish uniformity across genetic lines. Whether a sow had pigs transferred into her litter or from her litter to another litter was recorded, but the litter from which pigs came was not recorded. Therefore, the genetic line of pigs fostered unto a sow was not known.

Litters were weaned between 14 and $19 \mathrm{~d}$ of age with an average of $15 \mathrm{~d}$. At weaning, sows were removed to gestation facilities and the number of pigs in a litter (NW) and individual pig weights were recorded to determine the litter weaning weight (LWT).

\section{Culling and Replacement Female Procedures}

By program design, sows were removed only if they died, failed to conceive within $50 \mathrm{~d}$ after weaning, weaned their fourth parity, or were culled by the veterinarian for health reasons. As females were removed from the herd, replacement females of a new genetic line were introduced on an as-needed basis to maintain breeding herd size and pig flow targets. The replacement females were entered, introduced, and handled following the same health and management protocols of the original genetic lines.

\section{Statistical Analysis}

For the reader's convenience, Table 2 lists abbreviations used herein. Mixed model procedures (SAS Inst. Inc., Cary, NC) were used to analyze traits that were repeated measures of females. Sow reproductive traits included TB, NBA, SB, MUM, TBWT, and LBWT. Characteristics of sows recorded before and following lactation included gestation length (GEST), farrowing weight (FW), last-rib backfat depth at farrowing (BF), lactation feed intake (LFI), lactation weight loss (WTLOSS), and lactation backfat loss (BFLOSS). Females were assigned to contemporary groups to account for sources of environmental variation that affect reproductive performance. There were 86 contemporary groups, with each group including all sows that farrowed within $7-d$ periods beginning and running consecutively from when the first sow farrowed to when the final sow farrowed. The model included the fixed effects of genetic line, parity, breed-to-wean production unit (unit), and the interactions of genetic line $\times$ parity and genetic line $\times$ unit. Random effects included were the individual female and contemporary group within each unit. Lactation length was included as a linear covariate for WTLOSS, BFLOSS, and LFI in lactation. Records from the genetic line that served as the female replacement source when project females were culled were included in all analyses to increase numbers in each contemporary group and to produce groups of approximately equal size; however, results for this replacement genetic line are not reported.

In practice, sows of only one genetic line are likely to exist on any one farm, and it would not be possible to transfer pigs among sows of different genetic lines. Therefore, the practical comparisons of genetic lines for number weaned per litter and litter weaning weight is as if pigs were transferred only within line, in which case the mean number after transfer would be equal to the mean number born alive in the line. To make such comparisons, number weaned and litter weaning weight data only for litters in which no pigs were transferred into that litter were used ( $\mathrm{N}=5,536$ litter records). The Mixed procedures of SAS (SAS Inst. Inc.) were used. Data were first fitted to a model including the fixed effects of genetic line, production unit, and parity, the random effect of contemporary group, the 
Table 2. Trait descriptions

\begin{tabular}{lccl}
\hline \hline Trait & Abbreviation & Unit & \\
\hline Total born & TB & pig & Description \\
Total born alive & NBA & pig & Count of fully formed pigs plus stillborns \\
Total stillborns & SB & pig & Count of fully formed pigs born dead \\
Total mummified pigs & MUM & pig & Count of mummified fetuses \\
Total litter birth weight & TBWT & $\mathrm{kg}$ & Weight of litter including live and stillborn pigs \\
Live litter birth weight & LBWT & $\mathrm{kg}$ & Weight of litter including only live pigs \\
Number weaned & NW & $\mathrm{kg}$ & Count of pigs weaned at an average age of 15 d \\
Litter weaning weight & LWT & $\mathrm{kg}$ & Weight of litter at weaning \\
Lactation feed intake & LFI & $\mathrm{kg}$ & Lactating female feed intake \\
Farrow weight & FWT & $\mathrm{kg}$ & Female weight upon entering the farrowing facility \\
Lactation weight loss & WTLOSS & $\mathrm{mm}$ & Female lactation weight change from entry until weaning \\
Backfat depth at farrowing & BF & $\mathrm{mm}$ & Females lactation backfat change from entry to weaning \\
Backfat loss in lactation & BFLOSS & $\mathrm{d}$ & Number of days from parturition to weaning \\
Lactation length & LACT & $\mathrm{d}$ & Number of days from first mating until parturition \\
Gestation length & GEST & &
\end{tabular}

linear and quadratic regressions on number of pigs the sow was given an opportunity to raise (number after pigs had been transferred out, or number of live pigs per litter if no pigs were removed from the litter), the interaction of each of these regressions with genetic line and with parity, and the linear regression on lactation length. Interactions of regressions with both genetic line and parity existed for both traits $(P<0.05)$. Therefore, data for each parity were analyzed separately by fitting a model including genetic line, production unit, contemporary group, average linear regression on lactation length, and within-line linear and quadratic regressions on number of pigs the sow was given an opportunity to raise. Estimate and contrast statements were used to produce least squares means for each line at the mean number born alive for that line and to compare differences among these means. The procedure compares lines as if sows were raising only pigs of their own line adjusted to the mean number born alive for that line and pigs were weaned at $15 \mathrm{~d}$ of age.

Wean-to-service (WS) interval, measured as days from weaning to first mating, and farrowing interval (FI), measured as the number of days between successive farrowings, were analyzed using the GLM procedure of SAS (SAS Inst. Inc.). Fixed effects included genetic line, breed-to-wean unit, initial female entry group, and the interaction of genetic line $\times$ unit. To further describe the variation and distribution of WS interval within parity, records within parity were classified into three categories ( 0 to $10 \mathrm{~d}, 11$ to $50 \mathrm{~d}$, and $>50 \mathrm{~d}$ ) and the number and percentage of females within each category reported.

\section{Results and Discussion}

Arithmetic means and phenotypic standard deviations of variance components for random model effects are presented in Table 3. The observation numbers reported include information recorded on the replacement genetic line in addition to those for the six genetic lines tested and represent the total number of records used in the analysis of each trait.

Number of gilts entering the breeding herd, the percentage of females entering that expressed estrus, their age at first estrus, the percentage of females farrowing a first litter, and their age at first farrowing are summarized in Table 4. Line GPK347 gilts expressed estrus $13 \mathrm{~d}$ sooner $(P<0.05)$ and farrowed $12 \mathrm{~d}$ earlier $(P<$ $0.05)$ in life than gilts of the other five genetic lines. Interestingly, $92 \%$ of the GPK347 gilts that entered the breeding herd farrowed at least their first litter compared to an average of $76.6 \%$ for the other lines. In commercial production, where cost of replacement females is often high and recovery of the cost is a function of increasing the proportion of females that farrow one of more litters, a $15 \%$ increase in the proportion of females farrowing a litter from the GPK347 line will result in large differences in economic efficiency at the commercial level.

Large differences in the number of litters produced within the genetic line $\times$ parity subclasses (Table 5) were observed in the present study. Within a genetic line, parity differences were due to either death or a wean-to-service interval greater than $50 \mathrm{~d}$. Overall, GPK347 females farrowed more litters at each parity than any other line and produced more total litter records ( $\mathrm{n}=1,738)$ than the average of 1,337 records for the other five genetic lines.

\section{Litter Performance}

Genetic line differences (Table 6) were large for litter performance traits (TB, NBA, SB, MUM, TBWT, and LBWT; $P<0.01$ ). Parity differences (Table 6) existed for nearly all litter traits (TB, SB, MUM, TBWT, and LBWT; $P<0.01)$ except NBA $(P=0.27)$. However, genetic line $\times$ parity interactions (Table 7 ) existed for TB $(P<0.01)$, NBA $(P<0.01)$, TBWT $(P<0.001)$, and LBWT $(P<0.001)$. If producers were to use these lines, they would realize the average line effect across parities 
Table 3. Number of observations, mean, standard deviation, and range for traits measured

\begin{tabular}{lccrcc}
\hline \hline Trait $^{\text {a }}$ & Records & Unit & Mean & SD $^{\mathrm{b}}$ & Range \\
\hline TB & 11,111 & pig & 11.05 & 1.49 & 1 to 25 \\
NBA & 11,111 & pig & 9.96 & 1.38 & 0 to 21 \\
SB & 11,111 & pig & 0.81 & 0.57 & 0 to 15 \\
MUM & 11,111 & pig & 0.27 & 0.14 & 0 to 13 \\
TBWT & 10,982 & $\mathrm{~kg}$ & 16.61 & 2.25 & 0.45 to 32.73 \\
LBWT & 10,982 & $\mathrm{~kg}$ & 15.54 & 2.10 & 0.00 to 30.91 \\
NW & 10,982 & $\mathrm{pig}$ & 8.96 & 1.74 & 0 to 13 \\
LWT & 10,982 & $\mathrm{~kg}$ & 48.32 & 13.79 & 0.00 to 90.45 \\
LFI & 10,679 & $\mathrm{~kg}$ & 82.05 & 10.74 & 0.00 to 178.2 \\
FWT & 9,381 & $\mathrm{~kg}$ & 219.50 & 20.85 & 105.5 to 353.6 \\
WTLOSS & 8,038 & $\mathrm{~kg}$ & 22.30 & 9.86 & -26.8 to 68.2 \\
BF & 10,058 & $\mathrm{~mm}$ & 19.10 & 2.30 & 7.6 to 39.9 \\
BFLOSS & 9,047 & $\mathrm{~mm}$ & 1.28 & 1.76 & -8.1 to 13.0 \\
LACT & 10,984 & day & 15.00 & 1.79 & 0 to 32 \\
GEST & 8,432 & day & 116.10 & 0.98 & 106 to 124 \\
\hline
\end{tabular}

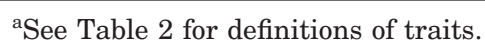

${ }^{\mathrm{b}} \mathrm{SD}=$ Square root of the sum of variance components for random effects in mixed model analyses after adjustment for fixed effects.

Table 4. Summary of females entering breed-to-wean facilities, percentage of females entering that expressed estrus, age at their first estrus, percentage of gilts entered that farrowing their first litter, and their age at first farrowing

\begin{tabular}{lccccc}
\hline \hline & $\begin{array}{c}\text { Number of } \\
\text { females entered } \\
\text { into breed-wean } \\
\text { facilities }\end{array}$ & $\begin{array}{c}\text { Expressed } \\
\text { estrus, \% }\end{array}$ & $\begin{array}{c}\text { Age at first } \\
\text { estrus, d }\end{array}$ & $\begin{array}{c}\text { Farrowed a } \\
\text { litter, \% }\end{array}$ & $\begin{array}{c}\text { Age at first } \\
\text { farrowing, d }\end{array}$ \\
\hline ADSG & 562 & 91 & $225^{\mathrm{z}}$ & 77 & $371^{\mathrm{z}}$ \\
DB & 541 & 87 & $222^{\mathrm{z}}$ & 77 & $366^{\mathrm{z}}$ \\
DK & 550 & 87 & $222^{\mathrm{z}}$ & 75 & $367^{\mathrm{z}}$ \\
GPK347 & 547 & 97 & $209^{\mathrm{y}}$ & 92 & $354^{\mathrm{y}}$ \\
NH & 568 & 88 & $223^{\mathrm{z}}$ & 78 & $368^{\mathrm{z}}$ \\
NSR & 515 & 90 & $222^{\mathrm{z}}$ & 76 & $367^{\mathrm{z}}$ \\
\hline
\end{tabular}

${ }^{\mathrm{a}} \mathrm{ADSG}=$ American Diamond Swine Genetics; DB = Danbred, USA; DK = DeKalb Monsanto DK44; GPK347 = DeKalb Monsanto GPK347; NSR = National Swine Registry; NH = Newsham Hybrids, USA.

${ }^{\mathrm{y}, \mathrm{z}}$ Within a column, means without a common superscript letter $\operatorname{differ}(P<0.05)$.

Table 5. Number of females that farrowed a litter within each genetic line by parity subclass

\begin{tabular}{lccccc}
\hline \hline & \multicolumn{5}{c}{ Parity } \\
\cline { 2 - 5 } Genetic line $^{\mathrm{a}}$ & 1 & 2 & 3 & 4 & Total \\
\hline ADSG & 434 & 362 & 323 & 265 & 1,384 \\
DB & 415 & 339 & 302 & 249 & 1,305 \\
DK & 413 & 359 & 313 & 248 & 1,333 \\
GPK347 & 500 & 451 & 418 & 369 & 1,738 \\
NH & 442 & 369 & 332 & 273 & 1,248 \\
NSR & 388 & 318 & 290 & 252 & 1,416 \\
Total & 2,592 & 2,198 & 1,948 & 1,656 & 8,424 \\
\hline
\end{tabular}

${ }^{\mathrm{a}} \mathrm{ADSG}=$ American Diamond Swine Genetics; DB = Danbred, USA; DK = DeKalb Monsanto DK44; GPK347 $=$ DeKalb Monsanto GPK347; NSR = National Swine Registry; NH = Newsham Hybrids, USA. 
Table 6. Genetic line and parity means for litter traits

\begin{tabular}{|c|c|c|c|c|c|c|}
\hline Fixed effect & Total born & $\begin{array}{l}\text { Number } \\
\text { born alive }\end{array}$ & $\begin{array}{l}\text { Number of } \\
\text { stillbirths }\end{array}$ & $\begin{array}{c}\text { Number of } \\
\text { mummified } \\
\text { piglets }\end{array}$ & $\begin{array}{l}\text { Total litter birth } \\
\text { weight, kg }\end{array}$ & $\begin{array}{l}\text { Live litter birth } \\
\text { weight, } \mathrm{kg}\end{array}$ \\
\hline \multicolumn{7}{|l|}{ Genetic line $^{\mathrm{a}}$} \\
\hline ADSG & $10.22 \pm 0.12^{\mathrm{z}}$ & $9.37 \pm 0.11^{\mathrm{y}}$ & $0.64 \pm 0.04^{\mathrm{v}}$ & $0.22 \pm 0.02^{\mathrm{vw}}$ & $16.56 \pm 0.16^{\mathrm{w}}$ & $15.71 \pm 0.16^{\mathrm{wx}}$ \\
\hline DB & $11.03 \pm 0.12^{\mathrm{x}}$ & $9.87 \pm 0.11^{\mathrm{x}}$ & $0.90 \pm 0.04^{\mathrm{w}}$ & $0.27 \pm 0.02^{\mathrm{wx}}$ & $17.40 \pm 0.17^{\mathrm{v}}$ & $16.24 \pm 0.17^{\mathrm{v}}$ \\
\hline $\mathrm{DK}$ & $11.56 \pm 0.12^{\mathrm{w}}$ & $10.35 \pm 0.11^{\mathrm{w}}$ & $0.95 \pm 0.04^{\mathrm{w}}$ & $0.26 \pm 0.02^{\mathrm{wx}}$ & $17.31 \pm 0.17^{\mathrm{v}}$ & $16.20 \pm 0.17^{\mathrm{vw}}$ \\
\hline NSR & $10.61 \pm 0.12^{\mathrm{y}}$ & $9.69 \pm 0.11^{\mathrm{x}}$ & $0.72 \pm 0.05^{\mathrm{v}}$ & $0.22 \pm 0.02^{\mathrm{vw}}$ & $16.70 \pm 0.17^{\mathrm{w}}$ & $15.75 \pm 0.17^{\mathrm{wx}}$ \\
\hline \multicolumn{7}{|l|}{ Parity } \\
\hline 1 & $11.07 \pm 0.09^{v}$ & $10.04 \pm 0.08$ & $0.77 \pm 0.03^{w}$ & $0.26 \pm 0.01^{\mathrm{w}}$ & $15.71 \pm 0.13^{\mathrm{w}}$ & $14.79 \pm 0.14^{\mathrm{x}}$ \\
\hline 2 & $10.79 \pm 0.09^{\mathrm{w}}$ & $9.89 \pm 0.08$ & $0.69 \pm 0.03^{v}$ & $0.20 \pm 0.01^{\mathrm{v}}$ & $17.13 \pm 0.13^{\mathrm{v}}$ & $16.20 \pm 0.13^{\mathrm{v}}$ \\
\hline 3 & $11.13 \pm 0.09^{v}$ & $10.00 \pm 0.08$ & $0.87 \pm 0.03^{x}$ & $0.29 \pm 0.01^{\mathrm{w}}$ & $17.35 \pm 0.13^{v}$ & $16.19 \pm 0.13^{\mathrm{v}}$ \\
\hline 4 & $11.08 \pm 0.13^{\mathrm{v}}$ & $9.83 \pm 0.08$ & $0.99 \pm 0.05^{\mathrm{y}}$ & $0.27 \pm 0.02^{\mathrm{w}}$ & $17.13 \pm 0.18^{\mathrm{v}}$ & $15.78 \pm 0.19^{\mathrm{w}}$ \\
\hline
\end{tabular}

${ }^{\mathrm{a} A D S G}=$ American Diamond Swine Genetics; DB = Danbred, USA; DK = DeKalb Monsanto DK44; GPK347 = DeKalb Monsanto GPK347; NSR = National Swine Registry; NH = Newsham Hybrids, USA.

$\mathrm{v}, \mathrm{w}, \mathrm{x}, \mathrm{y}, \mathrm{z}$ Within a fixed effect and column, means without a common superscript letter differ $(P<0.01)$.

if sows of each line have on average the same number of parities. However, if parity number differs among lines, then, because of interactions, line $\times$ parity effects are relevant. Therefore, both overall average line means and line $\times$ parity means are presented in the tables. Differences in production units were significant for all litter performance traits except number of mummified pigs per litter $(P=0.18)$. Genetic line $\times$ produc-

Table 7. Genetic line $\times$ parity interaction for total number of pigs born, number of live pigs per litter, total litter birth weight, and litter weight of live pigs

\begin{tabular}{|c|c|c|c|c|}
\hline \multirow[b]{2}{*}{ Genetic line $^{\mathrm{a}}$} & \multicolumn{4}{|c|}{ Parity } \\
\hline & 1 & 2 & 3 & 4 \\
\hline & & — Total numb & n per litter & \\
\hline $\mathrm{ADSG}$ & $10.09 \pm 0.18^{z}$ & $9.90 \pm 0.19^{\mathrm{yz}}$ & $10.16 \pm 0.19^{\mathrm{z}}$ & $10.72 \pm 0.21^{\mathrm{w}}$ \\
\hline $\mathrm{DB}$ & $11.10 \pm 0.18^{\mathrm{x}}$ & $10.74 \pm 0.19^{\mathrm{x}}$ & $11.52 \pm 0.20^{\mathrm{w}}$ & $10.77 \pm 0.22^{\mathrm{w}}$ \\
\hline DK & $11.59 \pm 0.18^{\mathrm{w}}$ & $11.44 \pm 0.18^{\mathrm{v}}$ & $11.56 \pm 0.20^{\mathrm{w}}$ & $11.66 \pm 0.22^{\mathrm{v}}$ \\
\hline GPK347 & $12.19 \pm 0.17^{\mathrm{v}}$ & $11.86 \pm 0.17^{\mathrm{v}}$ & $12.03 \pm 0.17^{\mathrm{v}}$ & $11.82 \pm 0.18^{\mathrm{v}}$ \\
\hline $\mathrm{NH}$ & $10.61 \pm 0.17^{\mathrm{y}}$ & $10.37 \pm 0.18^{\mathrm{wx}}$ & $10.50 \pm 0.19^{\mathrm{yz}}$ & $10.61 \pm 0.21^{\mathrm{w}}$ \\
\hline \multirow[t]{2}{*}{ NSR } & $11.08 \pm 0.19^{\mathrm{x}}$ & $10.23 \pm 0.20^{\mathrm{yz}}$ & $10.79 \pm 0.20^{\mathrm{xy}}$ & $10.37 \pm 0.22^{\mathrm{w}}$ \\
\hline & \multicolumn{4}{|c|}{ Number born alive per litter } \\
\hline $\mathrm{ADSG}$ & $9.32 \pm 0.17^{\mathrm{y}}$ & $9.16 \pm 0.18^{\mathrm{y}}$ & $9.39 \pm 0.19^{\mathrm{x}}$ & $9.61 \pm 0.20^{\mathrm{w}}$ \\
\hline $\mathrm{DB}$ & $10.02 \pm 0.17^{\mathrm{x}}$ & $9.80 \pm 0.18^{x}$ & $10.32 \pm 0.19^{\mathrm{w}}$ & $9.44 \pm 0.21^{\mathrm{w}}$ \\
\hline $\mathrm{DK}$ & $10.53 \pm 0.17^{\mathrm{w}}$ & $10.44 \pm 0.18^{\mathrm{w}}$ & $10.22 \pm 0.19^{\mathrm{w}}$ & $10.21 \pm 0.21^{\mathrm{v}}$ \\
\hline GPK347 & $11.07 \pm 0.16^{\mathrm{v}}$ & $10.97 \pm 0.16^{\mathrm{v}}$ & $10.84 \pm 0.17^{\mathrm{v}}$ & $10.38 \pm 0.18^{\mathrm{v}}$ \\
\hline $\mathrm{NH}$ & $9.84 \pm 0.17^{x}$ & $9.60 \pm 0.18^{\mathrm{x}}$ & $9.49 \pm 0.18^{\mathrm{x}}$ & $9.46 \pm 0.20^{\mathrm{w}}$ \\
\hline \multirow[t]{2}{*}{ NSR } & $10.03 \pm 0.18^{x}$ & $9.48 \pm 0.19^{\mathrm{xy}}$ & $9.85 \pm 0.19^{\mathrm{wx}}$ & $9.39 \pm 0.21^{\mathrm{w}}$ \\
\hline & \multicolumn{4}{|c|}{ — Total litter birth weight, $\mathrm{kg}$} \\
\hline $\mathrm{ADSG}$ & $15.51 \pm 0.25^{\mathrm{w}}$ & $16.67 \pm 0.26^{\mathrm{x}}$ & $16.78 \pm 0.27^{\mathrm{y}}$ & $17.38 \pm 0.29^{\mathrm{vw}}$ \\
\hline DB & $16.22 \pm 0.26^{\mathrm{v}}$ & $17.80 \pm 0.27^{\mathrm{v}}$ & $18.27 \pm 0.28^{\mathrm{vw}}$ & $17.46 \pm 0.30^{\mathrm{v}}$ \\
\hline $\mathrm{DK}$ & $16.18 \pm 0.25^{\mathrm{v}}$ & $17.93 \pm 0.26^{\mathrm{v}}$ & $17.84 \pm 0.27^{\mathrm{wx}}$ & $17.62 \pm 0.30^{\mathrm{v}}$ \\
\hline GPK347 & $15.31 \pm 0.24^{\mathrm{w}}$ & $17.18 \pm 0.24^{\mathrm{w}}$ & $17.29 \pm 0.24^{\mathrm{xy}}$ & $16.86 \pm 0.26^{\mathrm{w}}$ \\
\hline $\mathrm{NH}$ & $15.33 \pm 0.25^{\mathrm{w}}$ & $16.46 \pm 0.26^{\mathrm{x}}$ & $16.12 \pm 0.26^{\mathrm{z}}$ & $16.16 \pm 0.29^{\mathrm{x}}$ \\
\hline \multirow[t]{2}{*}{ NSR } & $16.32 \pm 0.26^{\mathrm{v}}$ & $16.78 \pm 0.27^{\mathrm{wx}}$ & $17.14 \pm 0.28^{\mathrm{y}}$ & $16.68 \pm 0.30^{\mathrm{wx}}$ \\
\hline & \multicolumn{4}{|c|}{ Litter weight of live pigs at birth, kg } \\
\hline $\mathrm{ADSG}$ & $14.83 \pm 0.25^{\mathrm{wx}}$ & $15.89 \pm 0.26^{\mathrm{wx}}$ & $15.94 \pm 0.27^{\mathrm{x}}$ & $16.20 \pm 0.29^{\mathrm{v}}$ \\
\hline $\mathrm{DB}$ & $15.27 \pm 0.26^{\mathrm{vw}}$ & $16.80 \pm 0.27^{\mathrm{v}}$ & $16.89 \pm 0.28^{\mathrm{v}}$ & $16.04 \pm 0.30^{\mathrm{vw}}$ \\
\hline DK & $15.22 \pm 0.25^{\mathrm{w}}$ & $16.84 \pm 0.26^{\mathrm{v}}$ & $16.50 \pm 0.27^{\mathrm{vw}}$ & $16.24 \pm 0.30^{\mathrm{v}}$ \\
\hline GPK347 & $14.45 \pm 0.24^{\mathrm{x}}$ & $16.32 \pm 0.24^{\mathrm{vw}}$ & $16.14 \pm 0.24^{\mathrm{wx}}$ & $15.39 \pm 0.26^{\mathrm{x}}$ \\
\hline $\mathrm{NH}$ & $14.56 \pm 0.24^{\mathrm{x}}$ & $15.67 \pm 0.26^{\mathrm{x}}$ & $15.14 \pm 0.26^{\mathrm{y}}$ & $15.07 \pm 0.29^{x}$ \\
\hline NSR & $15.40 \pm 0.26^{\mathrm{vw}}$ & $15.90 \pm 0.27^{\mathrm{wx}}$ & $16.11 \pm 0.28^{\mathrm{wx}}$ & $15.59 \pm 0.30^{\mathrm{wx}}$ \\
\hline
\end{tabular}

${ }^{\mathrm{a} A D S G}=$ American Diamond Swine Genetics; DB = Danbred, USA; DK= DeKalb Monsanto DK44; GPK347 $=$ DeKalb Monsanto GPK347; NSR = National Swine Registry; NH = Newsham Hybrids, USA.

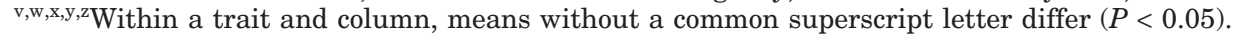


tion unit interactions were not significant for any litter trait.

Total number of pigs born per litter, the upper limit for genetic potential for NBA, is a function of ovulation rate, number of eggs fertilized, and embryonic and fetal survival. Differences between number of pigs born alive and total born per litter are due to effects of uterine environment late in gestation, length of the farrowing period, and management at parturition that may result in stillborn pigs. Number born alive has the greatest economic value as it establishes the upper limit for the number of market pigs. Across parities, GPK347 sows had greater TB and NBA than all other lines $(P<0.05)$, with advantages over DK females of 0.42 total born and 0.47 live born pigs, and DK sows averaged significantly more TB and NBA than the remaining lines, with advantages of $1.34 \mathrm{~TB}$ and $0.98 \mathrm{NBA}$ over the ADSG females that had the smallest litters. Averaged across lines, TB in Parity $2(10.79 \pm 0.09)$ was less $(P<0.05)$ than in Parities 1, 3, and 4 (11.09 \pm 0.06$)$.

Genetic lines with the greatest number of TB per litter also had the greatest number of SB pigs (DB, DK, and GPK347). Uterine environment late in gestation and/or extended length of parturition due to a larger number of fetuses farrowed may have played a role in the observed increase in number of SB pigs. Ruiz-Flores and Johnson (2001) reported genetic and phenotypic correlations of 0.20 and 0.33 , respectively, between number of stillborn and fully formed pigs, which is consistent with the relationship across breeds observed in the present trial. There were also fewer SB $(P<0.01)$ and MUM $(P<0.01)$ pigs in Parity 2 , a parity in which TB was also less $(P<0.01)$.

Large litter birth weights result from a large number of and/or heavy individual piglet birth weights. In the absence of dystocia, heavier pig birth weights improve piglet viability and have positive effects on subsequent growth rate (Roehe, 1999). Genetic lines differed for both TBWT and LBWT in the present study. Danbred and DK females produced the heaviest $(P<0.05)$ litters across all parities. Although the LBWT of litters produced by GPK347 sows was intermediate to that of the other genetic lines, the data indicate that this was due to an increased number of pigs per litter and not average pig weight. Average pig weights (LBWT $\div$ NBA) were lighter for litters by GPK 347 sows (1.44 kg) compared to a range from 1.57 to $1.68 \mathrm{~kg} / \mathrm{pig}$ for litters by sows of the other genetic lines. The heaviest pigs at birth were by ADSG sows, the line with the fewest NBA. Ruiz-Flores and Johnson (2001) reported a large, negative $(r=-0.95)$ genetic correlation between direct genetic effects of the dam on number of fully formed pigs and maternal effects of the dam on individual pig birth weights, and this is consistent with the ranking for calculated average pig weight of the genetic lines in the present experiment. Kerr and Cameron (1995) and Roehe (1999) also reported that individual birth weight decreased with increased number born alive. Roehe (1999) reported a large reduction in preweaning mortality as pig birth weight increased, and increased preweaning and early postweaning growth for larger pigs at birth. Because only total litter weights were recorded, the effect of individual pig birth weight on subsequent performance could not be assessed.

Total litter birth weight increased $(P<0.01)$ from Parity 1 to 2 and remained steady from Parities 2 through 4 . Live litter birth weight increased $(P<0.01)$ from Parity 1 to 2, remained steady at Parities 2 and 3 and declined $(P<0.01)$ in Parity 4 . The reduction in LBWT in Parity 4 may have been due to an extended duration of the farrowing process in larger, heavier sows that may have contributed to the observed increase $(P<0.05)$ in number of SB in litters by Parity 4 sows.

The genetic line $\times$ parity interaction (Table 7 ) for TB $(P<0.01)$ and NBA $(P<0.01)$ occurred primarily because of a change in rank of the DB line across parities and, to a lesser degree, to a reduction in the magnitude of the difference among genetic lines in Parity 4 compared with Parity 1. Total born in litters by DB sows was intermediate at Parities 1 and 2 , increased $(P<$ 0.05 ) and was not different from the second-highest performing line at Parity 3 , and declined and was not significantly different from the poorest-performing lines at Parity 4 . The GPK347 sows had the greatest $(P<0.05)$ TB at Parities 1 and 3 , and produced greater $(P<0.05)$ TB than all other sows except the DK sows at Parities 2 and 4. The ADSG sows ranked lowest for TB at all parities, having fewer $(P<0.05)$ TB than all other genetic lines in Parities 1 and 3. Mean separation procedures produced five distinct groups at Parity 1. At Parity 4, lines were grouped into only two classes.

Genetic line $\times$ parity interactions for NBA and TB were similar. The mean NBA for DB sows was intermediate at Parities 1 and 2 and then, compared with other sow lines, increased at Parity 3 and decreased at Parity 4. Again, GPK347 sows had greater $(P<0.05)$ NBA than all other genetic lines at Parities 1 through 3 , but, compared with their previous litters, NBA declined $(P$ $<0.05$ ) at Parity 4 when their mean NBA was not different from that of DK line sows. The range among line means for NBA was similar at Parities 1 and 2 but declined at Parities 3 and 4 so that only two distinct classes existed at Parity 4.

Differences among line means in TBWT and LBWT increased from Parity 1 through Parity 3 and declined in Parity 4. There were two distinct classes at Parity 1, three distinct classes in Parity 4, and greater variation among lines at Parities 2 and 3. The greatest shift in rank occurred for ADSG sows that were in the class of lightest litters at Parity 1 but were in the heaviest class at Parity 4. Increased TBWT and LBWT observed for litters by Parity 4 ADSG sows were due to an increase in pig weights as ADSG sows produced fewer $(P<0.05)$ pigs at Parity 4 than other genetic lines. The $\mathrm{NH}$ sows had low TBWT and LBWT at all parities.

The primary indicators of sow mothering and milking ability are the number of pigs weaned and litter wean- 
Table 8. Genetic line effects for number of pigs weaned per litter and litter weaning weight by parity

\begin{tabular}{|c|c|c|c|c|}
\hline \multirow[b]{2}{*}{ Genetic line $\mathrm{e}^{\mathrm{a}}$} & \multicolumn{4}{|c|}{ Parity } \\
\hline & 1 & 2 & 3 & 4 \\
\hline & & Number & per litter & \\
\hline $\mathrm{ADSG}$ & $8.63 \pm 0.11^{\mathrm{z}}$ & $8.48 \pm 0.10^{y}$ & $8.77 \pm 0.10^{\mathrm{y}}$ & $8.89 \pm 0.11^{x y}$ \\
\hline $\mathrm{DB}$ & $8.92 \pm 0.11^{\mathrm{xy}}$ & $8.54 \pm 0.09^{y}$ & $9.49 \pm 0.10^{\mathrm{w}}$ & $8.83 \pm 0.12^{x y}$ \\
\hline DK & $9.19 \pm 0.10^{\mathrm{w}}$ & $9.40 \pm 0.09^{w}$ & $9.05 \pm 0.10^{\mathrm{x}}$ & $9.01 \pm 0.11^{x}$ \\
\hline GPK347 & $9.13 \pm 0.10^{\mathrm{wx}}$ & $9.56 \pm 0.08^{w}$ & $9.58 \pm 0.08^{w}$ & $9.29 \pm 0.10^{\mathrm{w}}$ \\
\hline $\mathrm{NH}$ & $8.80 \pm 0.10^{\mathrm{yz}}$ & $8.87 \pm 0.09^{x}$ & $8.67 \pm 0.10^{\mathrm{y}}$ & $8.92 \pm 0.11^{x}$ \\
\hline \multirow[t]{2}{*}{ NSR } & $8.75 \pm 0.10^{\mathrm{yz}}$ & $8.78 \pm 0.10^{\mathrm{x}}$ & $8.99 \pm 0.10^{\mathrm{x}}$ & $8.65 \pm 0.12^{\mathrm{y}}$ \\
\hline & \multicolumn{4}{|c|}{ Litter weaning weight, $\mathrm{kg}$} \\
\hline $\mathrm{ADSG}$ & $46.9 \pm 0.8^{w}$ & $51.8 \pm 0.8^{\mathrm{w}}$ & $52.0 \pm 0.9^{w x}$ & $50.2 \pm 0.9^{\mathrm{w}}$ \\
\hline $\mathrm{DB}$ & $46.9 \pm 0.7^{\mathrm{w}}$ & $52.0 \pm 0.7^{\mathrm{w}}$ & $53.2 \pm 0.8^{\mathrm{w}}$ & $50.1 \pm 0.9^{\mathrm{w}}$ \\
\hline DK & $46.2 \pm 0.7^{\mathrm{w}}$ & $50.7 \pm 0.7^{\mathrm{wx}}$ & $48.9 \pm 0.8^{y}$ & $47.9 \pm 0.9^{x}$ \\
\hline GPK347 & $43.8 \pm 0.7^{x}$ & $49.9 \pm 0.7^{x}$ & $49.2 \pm 0.7^{\mathrm{y}}$ & $47.5 \pm 0.8^{\mathrm{x}}$ \\
\hline $\mathrm{NH}$ & $45.3 \pm 0.7^{w}$ & $50.3 \pm 0.7^{\mathrm{wx}}$ & $48.7 \pm 0.9^{y}$ & $48.5 \pm 0.9^{\mathrm{wx}}$ \\
\hline NSR & $45.9 \pm 0.7^{\mathrm{w}}$ & $51.6 \pm 0.8^{\mathrm{w}}$ & $51.0 \pm 0.9^{x}$ & $48.2 \pm 1.00^{\mathrm{wx}}$ \\
\hline
\end{tabular}

${ }^{a}$ ADSG = American Diamond Swine Genetics; DB = Danbred, USA; DK = DeKalb Monsanto DK44; GPK347 $=$ DeKalb Monsanto GPK347; NSR = National Swine Registry; NH = Newsham Hybrids, USA.

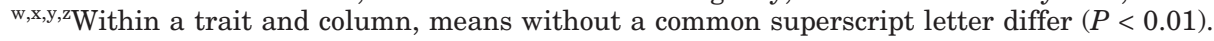

ing weight. Genetic lines were compared for NW and LWT as if litters of each line were standardized to the line mean number of live pigs per litter with a 15 -d lactation length. Because of significant interactions of regressions on number after transfer with line and parity, lines were compared within parity (Table 8).

Dekalb and GPK347 sows weaned the most pigs ( $P$ $<0.05)$ at Parities 1 and 2, GPK347 and DB sows weaned the most $(P<0.05)$ at Parity 3 , and the GPK347 sows weaned more $(P<0.05)$ pigs at Parity 4 . The ranges of line differences in NW at Parities 1 to 4 were $0.56,1.08,0.51$, and 0.65 pigs per litter, respectively. These relatively large differences in NW are due to differences in the number of pigs born alive and the mothering ability of sows.

Lines also differed in LWT, but lines ranked differently than for NW. The GPK347 sows tended to have lighter litters for each parity than sows of other genetic lines despite having the largest litters. Thus, the difference was due to lesser weights of pigs in litters nursed by GPK347 sows. The ADSG, DB, and NSR lines had the heaviest $(P<0.05)$ litters at weaning at all four parities. The DK sows were generally intermediate but varied most in rank across parities. Because creep feeding was not practiced, lesser litter weaning weights by GPK347 sows indicate that they produced less milk than other lines; however, it did not seem to affect piglet survival to weaning. Lesser individual pig weights at birth also likely contributed to the lesser LWT for litters by GPK347 sows. The opposite effect occurred for ADSG sows. They weaned the fewest pigs, but LWT was always in the class with heaviest litters, indicating they had superior milk production and produced heavy pigs at weaning.

\section{Female Traits}

Models of sow feed intake require estimates of sow weights at farrowing and changes in body condition during lactation in addition to litter production traits. To provide inputs into these models for specific lines, these traits along with observed feed intake were recorded. Means for genetic lines averaged across parities are presented in Table 9 , and line $\times$ parity means are in Table 10. Genetic lines differed $(P<0.01)$ for $\mathrm{FW}$, BF, LFI, WTLOSS, and BFLOSS. Parity also affected these traits, and genetic line $\times$ parity interactions existed for $\mathrm{BF}(P<0.001)$, FW $(P<0.001)$, LFI $(P<0.001)$, and WTLOSS $(P<0.01)$. Means for FW $(P<0.01)$, LFI $(P<0.01)$, and WTLOSS $(P<0.001)$ also differed between production units and genetic line $\times$ unit interactions occurred $(P<0.01)$ for these traits. These interactions were largely due to changes in magnitude of line differences between units and not to changes in rank.

Averaged across parities, DK females had greater $(P$ $<0.05) \mathrm{FW}$ and GPK347 females had less $(P<0.05)$ FW than all other genetic lines (Table 9). Lower FW of GPK347 females was at least partially because they were younger at first estrus $(P<0.05$; Table 4$)$ and thus younger $(P<0.05$; Table 4$)$ when they farrowed their first litter. They also rebred in shorter intervals than other lines (Table 11) and thus were younger at each subsequent litter. Sow farrowing weights increased $(P$ $<0.01$ ) with increased parity number. Interactions of genetic line $\times$ parity were observed and were primarily the result of changes in rank of lines with intermediate weights at farrowing (ADSG, DB, NSR, and NH; Table 10 ) and a slight increase in the range of FW from the lightest to heaviest for genetic line as parity number increased from Parity 1 (27 kg range) to Parity 4 (38 
Table 9. Genetic line and parity effects for weight (FW) and backfat depth (BF) at farrowing and feed intake (LFI), weight loss (WTLOSS) and backfat loss (BFLOSS) during lactation

\begin{tabular}{|c|c|c|c|c|c|}
\hline \multirow[b]{2}{*}{ Fixed effect } & \multicolumn{5}{|c|}{ Trait } \\
\hline & $\mathrm{FW}, \mathrm{kg}$ & $\mathrm{BF}, \mathrm{mm}$ & LFI, kg & WTLOSS, kg & BFLOSS, mm \\
\hline \multicolumn{6}{|l|}{ Genetic line $^{\mathrm{a}}$} \\
\hline ADSG & $230.2 \pm 1.3^{\mathrm{w}}$ & $23.1 \pm 0.2^{\mathrm{v}}$ & $86.8 \pm 0.7^{\mathrm{v}}$ & $21.9 \pm 0.8^{\mathrm{w}}$ & $1.44 \pm 0.12^{\mathrm{wx}}$ \\
\hline DB & $223.9 \pm 1.3^{\mathrm{x}}$ & $16.7 \pm 0.2^{\mathrm{z}}$ & $84.4 \pm 0.7^{\mathrm{wx}}$ & $21.7 \pm 0.8^{w}$ & $1.02 \pm 0.12^{\mathrm{y}}$ \\
\hline $\mathrm{DK}$ & $239.2 \pm 1.3^{\mathrm{v}}$ & $20.8 \pm 0.2^{\mathrm{w}}$ & $85.7 \pm 0.7^{\mathrm{vw}}$ & $21.4 \pm 0.8^{\mathrm{w}}$ & $1.27 \pm 0.12^{\mathrm{xy}}$ \\
\hline GPK347 & $205.4 \pm 1.2^{\mathrm{y}}$ & $19.8 \pm 0.2^{\mathrm{x}}$ & $77.9 \pm 0.7^{\mathrm{y}}$ & $24.7 \pm 0.8^{\mathrm{v}}$ & $1.89 \pm 0.11^{\mathrm{v}}$ \\
\hline $\mathrm{NH}$ & $222.4 \pm 1.3^{x}$ & $17.8 \pm 0.2^{\mathrm{y}}$ & $84.0 \pm 0.7^{x}$ & $19.7 \pm 0.8^{\mathrm{w}}$ & $1.04 \pm 0.12^{\mathrm{y}}$ \\
\hline NSR & $222.4 \pm 1.3^{\mathrm{x}}$ & $20.6 \pm 0.2^{\mathrm{w}}$ & $83.0 \pm 0.7^{x}$ & $21.4 \pm 0.8^{\mathrm{w}}$ & $1.58 \pm 0.12^{\mathrm{w}}$ \\
\hline \multicolumn{6}{|l|}{ Parity } \\
\hline 1 & $205.3 \pm 1.1^{\mathrm{v}}$ & $20.7 \pm 0.2^{\mathrm{v}}$ & $70.8 \pm 0.7^{y}$ & $24.2 \pm 0.8^{\mathrm{w}}$ & $1.86 \pm 0.13^{\mathrm{x}}$ \\
\hline 2 & $222.3 \pm 1.0^{\mathrm{w}}$ & $19.5 \pm 0.2^{\mathrm{w}}$ & $83.8 \pm 0.6^{\mathrm{x}}$ & $21.4 \pm 0.8^{v}$ & $1.27 \pm 0.11^{\mathrm{w}}$ \\
\hline 3 & $233.6 \pm 1.0^{\mathrm{x}}$ & $18.8 \pm 0.2^{\mathrm{x}}$ & $89.8 \pm 0.6^{\mathrm{w}}$ & $20.9 \pm 0.8^{v}$ & $1.08 \pm 0.12^{\mathrm{w}}$ \\
\hline 4 & $242.0 \pm 1.4^{\mathrm{y}}$ & $17.9 \pm 0.2^{\mathrm{y}}$ & $91.1 \pm 0.8^{\mathrm{v}}$ & $21.0 \pm 1.4^{\mathrm{v}}$ & $0.45 \pm 0.17^{\mathrm{v}}$ \\
\hline
\end{tabular}

${ }^{\mathrm{a}} \mathrm{ADSG}=$ American Diamond Swine Genetics; DB = Danbred, USA; DK = DeKalb Monsanto DK44; GPK347 $=$ DeKalb Monsanto GPK347; NSR = National Swine Registry; NH = Newsham Hybrids, USA.

$\mathrm{v}, \mathrm{W}, \mathrm{x}, \mathrm{y}, \mathrm{Z}$ Within a fixed effect and column, means without a common superscript letter differ $(P<0.01)$.

Table 10. Genetic line by parity means for farrowing weight, backfat depth at farrowing, lactation feed intake, and lactation weight loss

\begin{tabular}{|c|c|c|c|c|}
\hline \multirow[b]{2}{*}{ Genetic line ${ }^{a}$} & \multicolumn{4}{|c|}{ Parity } \\
\hline & 1 & 2 & 3 & 4 \\
\hline & & - Farrow & ht, $\mathrm{kg}$ & \\
\hline $\mathrm{ADSG}$ & $210.2 \pm 1.7^{\mathrm{w}}$ & $226.9 \pm 1.7^{\mathrm{x}}$ & $237.6 \pm 1.7^{\mathrm{x}}$ & $245.9 \pm 1.8^{\mathrm{x}}$ \\
\hline $\mathrm{DB}$ & $205.6 \pm 1.7^{x}$ & $221.8 \pm 1.7^{\mathrm{y}}$ & $230.6 \pm 1.7^{\mathrm{y}}$ & $238.2 \pm 1.9^{\mathrm{yz}}$ \\
\hline $\mathrm{DK}$ & $216.9 \pm 1.7^{\mathrm{w}}$ & $235.3 \pm 1.7^{\mathrm{w}}$ & $248.0 \pm 1.7^{\mathrm{w}}$ & $256.6 \pm 1.9^{w}$ \\
\hline GPK347 & $189.2 \pm 1.6^{\mathrm{y}}$ & $203.0 \pm 1.6^{\mathrm{z}}$ & $211.0 \pm 1.5^{\mathrm{z}}$ & $218.5 \pm 1.6^{\mathrm{e}}$ \\
\hline $\mathrm{NH}$ & $205.0 \pm 1.7^{\mathrm{x}}$ & $219.3 \pm 1.7^{\mathrm{y}}$ & $229.0 \pm 1.6^{\mathrm{y}}$ & $236.5 \pm 1.8^{z}$ \\
\hline \multirow[t]{2}{*}{ NSR } & $207.2 \pm 1.7^{\mathrm{x}}$ & $221.1 \pm 1.7^{\mathrm{y}}$ & $232.4 \pm 1.7^{\mathrm{y}}$ & $240.6 \pm 1.8^{\mathrm{xy}}$ \\
\hline & \multicolumn{4}{|c|}{ - Backfat depth at farrowing, $\mathrm{mm}$} \\
\hline $\mathrm{ADSG}$ & $25.0 \pm 0.3^{\mathrm{z}}$ & $23.7 \pm 0.3^{\mathrm{e}}$ & $22.6 \pm 0.3^{\mathrm{e}}$ & $21.2 \pm 0.3^{\mathrm{e}}$ \\
\hline $\mathrm{DB}$ & $17.8 \pm 0.3^{\mathrm{w}}$ & $16.8 \pm 0.3^{\mathrm{w}}$ & $16.3 \pm 0.3^{\mathrm{w}}$ & $15.7 \pm 0.3^{\mathrm{w}}$ \\
\hline $\mathrm{DK}$ & $22.3 \pm 0.3^{y}$ & $21.0 \pm 0.3^{z}$ & $20.3 \pm 0.3^{z}$ & $19.6 \pm 0.3^{z}$ \\
\hline GPK347 & $22.1 \pm 0.3^{y}$ & $19.8 \pm 0.3^{y}$ & $19.1 \pm 0.3^{y}$ & $18.4 \pm 0.3^{y}$ \\
\hline $\mathrm{NH}$ & $19.1 \pm 0.3^{\mathrm{x}}$ & $18.0 \pm 0.3^{\mathrm{x}}$ & $17.2 \pm 0.3^{\mathrm{x}}$ & $16.8 \pm 0.3^{\mathrm{x}}$ \\
\hline \multirow[t]{2}{*}{ NSR } & $21.8 \pm 0.3^{y}$ & $20.7 \pm 0.3^{z}$ & $20.4 \pm 0.3^{\mathrm{z}}$ & $19.4 \pm 0.3^{z}$ \\
\hline & \multicolumn{4}{|c|}{ Lactation feed intake, $\mathrm{kg}$} \\
\hline $\mathrm{ADSG}$ & $73.1 \pm 1.0^{\mathrm{w}}$ & $87.1 \pm 1.0^{\mathrm{w}}$ & $93.4 \pm 1.0^{\mathrm{w}}$ & $93.7 \pm 1.1^{\mathrm{wx}}$ \\
\hline $\mathrm{DB}$ & $70.5 \pm 1.0^{\mathrm{x}}$ & $82.3 \pm 1.0^{\mathrm{y}}$ & $90.5 \pm 1.0^{\mathrm{x}}$ & $94.2 \pm 1.1^{\mathrm{w}}$ \\
\hline DK & $73.5 \pm 1.0^{\mathrm{w}}$ & $85.4 \pm 1.0^{\mathrm{wx}}$ & $92.3 \pm 1.0^{\mathrm{w}}$ & $91.4 \pm 1.1^{\mathrm{xy}}$ \\
\hline GPK347 & $63.3 \pm 1.0^{\mathrm{y}}$ & $77.9 \pm 0.9^{\mathrm{z}}$ & $84.0 \pm 0.9^{y}$ & $86.5 \pm 1.0^{z}$ \\
\hline $\mathrm{NH}$ & $70.6 \pm 1.0^{\mathrm{x}}$ & $83.8 \pm 0.9^{x y}$ & $90.3 \pm 1.0^{\mathrm{x}}$ & $91.3 \pm 1.1^{\mathrm{xy}}$ \\
\hline \multirow[t]{2}{*}{ NSR } & $70.0 \pm 1.1^{\mathrm{x}}$ & $84.5 \pm 1.0^{\mathrm{xy}}$ & $88.8 \pm 1.0^{\mathrm{x}}$ & $88.9 \pm 1.1^{\mathrm{y}}$ \\
\hline & \multicolumn{4}{|c|}{ — Lactation weight loss, $\mathrm{kg}$} \\
\hline $\mathrm{ADSG}$ & $24.8 \pm 1.2^{\mathrm{xy}}$ & $20.7 \pm 1.3^{\mathrm{wx}}$ & $19.2 \pm 1.2^{\mathrm{w}}$ & $22.9 \pm 1.4^{\mathrm{x}}$ \\
\hline $\mathrm{DB}$ & $25.0 \pm 1.2^{\mathrm{xy}}$ & $21.9 \pm 1.4^{\mathrm{x}}$ & $20.5 \pm 1.3^{\mathrm{w}}$ & $19.6 \pm 1.5^{\mathrm{w}}$ \\
\hline $\mathrm{DK}$ & $23.2 \pm 1.2^{\mathrm{wx}}$ & $20.2 \pm 1.3^{\mathrm{wx}}$ & $20.0 \pm 1.3^{\mathrm{w}}$ & $22.2 \pm 1.4^{\mathrm{w}}$ \\
\hline GPK347 & $27.1 \pm 1.2^{\mathrm{y}}$ & $26.3 \pm 1.2^{\mathrm{y}}$ & $23.5 \pm 1.1^{\mathrm{x}}$ & $21.8 \pm 1.2^{\mathrm{w}}$ \\
\hline $\mathrm{NH}$ & $21.9 \pm 1.2^{\mathrm{w}}$ & $18.4 \pm 1.3^{\mathrm{w}}$ & $18.7 \pm 1.2^{\mathrm{w}}$ & $19.6 \pm 1.4^{\mathrm{w}}$ \\
\hline NSR & $24.9 \pm 1.2^{\mathrm{xy}}$ & $19.7 \pm 1.4^{\mathrm{wx}}$ & $20.4 \pm 1.3^{\mathrm{w}}$ & $20.5 \pm 1.4^{\mathrm{w}}$ \\
\hline
\end{tabular}

${ }^{\mathrm{a} A D S G}=$ American Diamond Swine Genetics; DB = Danbred, USA; DK = DeKalb Monsanto DK44; GPK347 $=$ DeKalb Monsanto GPK347; NSR = National Swine Registry; NH = Newsham Hybrids, USA.

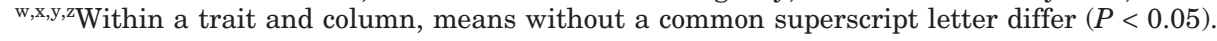


Table 11. Genetic line means for postfarrowing reproductive performance following Parities 1, 2, and 3

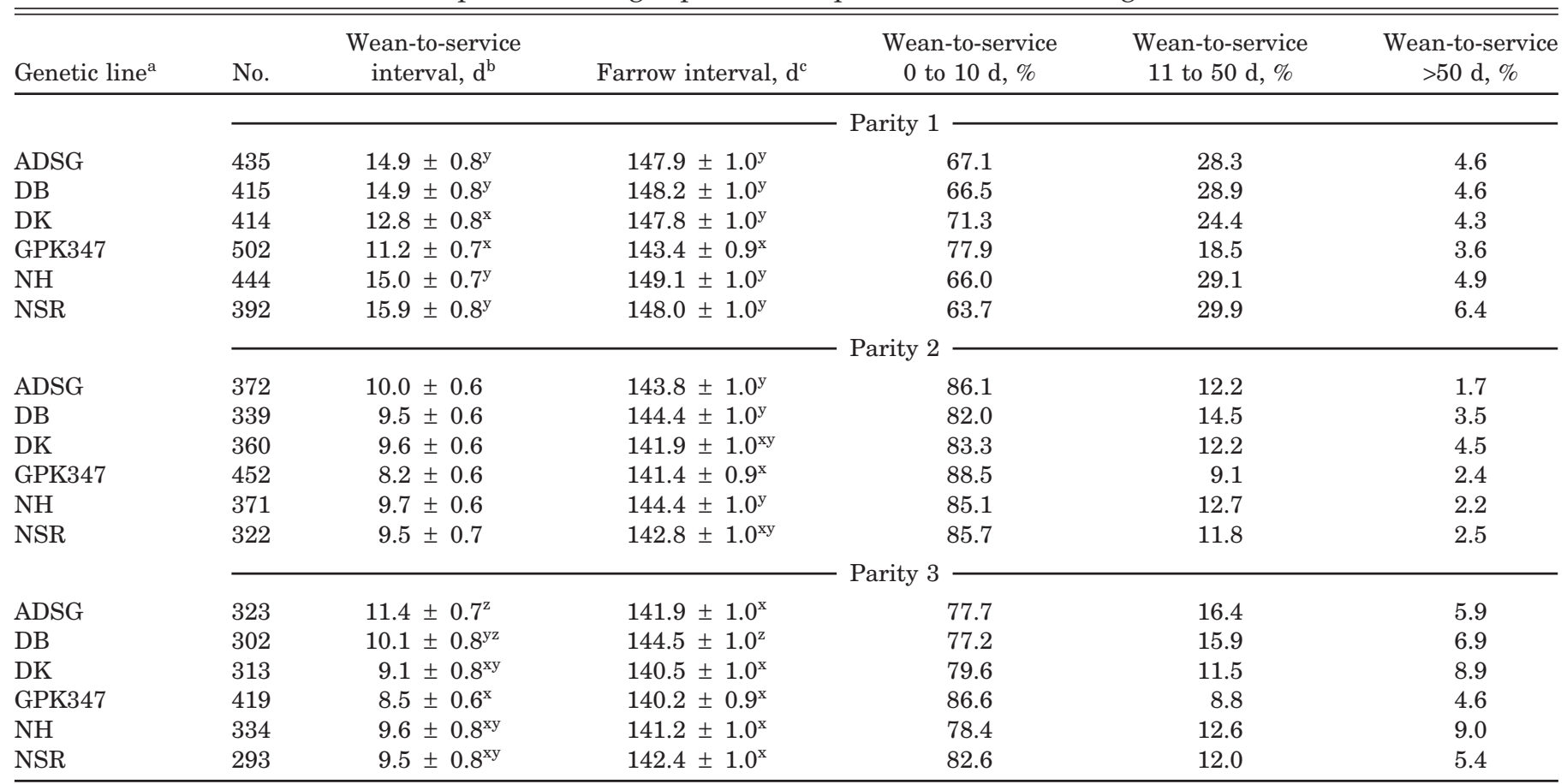

${ }^{\mathrm{a} A D S G}=$ American Diamond Swine Genetics; DB = Danbred, USA; DK = DeKalb Monsanto DK44; GPK347 = DeKalb Monsanto GPK347; NSR = National Swine Registry; NH = Newsham Hybrids, USA.

${ }^{\mathrm{b}}$ Wean-to-service interval $=$ time in days from weaning to first mating.

${ }^{c}$ Farrow interval $=$ time in days from one parturition to the next.

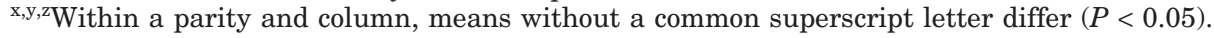

kg range). The GPK347 sows weighed the least and DK sows the most when farrowing across all parities.

Large line differences in $\mathrm{BF}$ of sows at farrowing (Table 9) existed. A range of $6.4 \mathrm{~mm}$ between the means of the leanest (DB) and fattest (ADSG) genetic lines ( $P$ $<0.05)$ existed. Averaged across parities, ADSG sows had greater $(P<0.05) \mathrm{BF}$ and DK sows had less $(P<$ $0.05) \mathrm{BF}$ at farrowing than other genetic lines.

Lines differed for both LFI $(P<0.01)$ and WTLOSS $(P<0.01)$ during lactation. The ADSG and DK sows were heaviest $(P<0.05)$ at farrowing and had greater $(P<0.05)$ LFI than other genetic lines. Sows of lines with moderate to high LFI (ADSG, DB, and DK) had similar WTLOSS. Sows of the GPK347 line ate the least feed during lactation $(77.9 \mathrm{~kg} ; P<0.05)$ and had the greatest WTLOSS $(24.7 \mathrm{~kg} ; P<0.05)$ during lactation. Except for DK sows, mean LFI closely paralleled sow FW. Mean LFI as a percentage of FW was $35.8 \%$ for DK sows and ranged from 37.3 to $37.9 \%$ for the other genetic lines. However, a different relationship existed for weight loss during lactation. The GPK347 sows lost $24.7 \mathrm{~kg}$ of weight during lactation, more $(P<0.05)$ than the other lines. The other lines did not differ in lactation weight loss and had mean losses from 21.4 to $21.9 \mathrm{~kg}$. The weight loss for GPK 347 sows was $12.0 \%$ of their farrowing weight, whereas weight loss for sows of other lines was between 8.9 and $9.7 \%$ of their farrowing weight.

Line differences in BFLOSS in lactation were related to $\mathrm{BF}$ at farrowing. Fatter lines tended to lose more absolute amounts of backfat depth than leaner ones. As a percentage of $\mathrm{BF}$ at farrowing, BFLOSS was $9.6 \%$ for GPK347 sows, 7.7\% for NH sows, and between 5.8 and $6.2 \%$ for sows of other lines. Although the GPK347 sows lost more $(P<0.05)$ weight and backfat $(P<0.05)$, they weaned larger $(P<0.05$; Table 8$)$ numbers of pigs at each parity than other lines, but LWT weaned tended to be less $(P<0.05$; Table 8$)$ than for other lines. In addition, GPK 347 females tended to rebreed sooner (Table 11) after their litters were weaned. The results of the present study are in contrast to those reported by Koketsu et al. (1996) who, in a summary of 24,320 records of lactation feed intake patterns and subsequent reproductive performance data, reported that sows with low feed intake throughout lactation or low feed intake within the first week of lactation followed by high feed intake had longer log-transformed weanto-service intervals and wean-to-conception interval when compared to sows that exhibited high intake throughout lactation, a rapid increase in lactation feed intake throughout lactation, or a gradual feed intake increase throughout lactation. Guedes and Nogueira (1996) reported no correlation between backfat loss in lactation and subsequent wean-to-estrus interval in primiparous and multiparous sows, which seems to support the findings of the present study.

Backfat depth decreased $(P<0.01)$ as parity increased even though farrowing weight increased $(P<$ 0.01 ) with parity. As sows of all lines aged, the absolute level of $\mathrm{BF}$ and the percentage of $\mathrm{BF}$ relative to $\mathrm{FW}$ 
decreased. Lactation feed intake for sows of all lines increased with increased parity number, due, at least in part, to increased FW. However, weight loss during lactation was greatest at Parity 1 , declined at Parity 2 , and then remained at that amount through Parity 4. Backfat loss was greatest in Parity $1(1.86 \mathrm{~mm} ; P<$ 0.05 ), decreased, but was not different in subsequent parities to a point where in Parity 4 only $0.45 \mathrm{~mm}$ of backfat was lost in lactation.

Genetic line $\times$ parity interactions for $\mathrm{BF}(P<0.01)$, LFI $(P<0.01)$, and WTLOSS $(P<0.01)$ were observed (Table 10). The interaction for $\mathrm{BF}$, although significant, had little effect on the ranking of the genetic lines within parity. The only changes in BF rank occurred for the NSR and DK lines in Parities 2 through 4 relative to GPK347 line female BF levels. Rank changes involving the DB and NSR lines across parity contributed to the interaction for LFI. The DB female line had greater LFI in Parity 4 than all lines except ADSG, whereas in Parities 1 through 3, DB sows had intermediate feed intake. Relative to the other genetic lines, LFI declined for NSR sows in Parity 4 . The genetic line $\times$ parity interaction for WTLOSS occurred because WTLOSS for GPK347 sows was greater $(P<0.05)$ in Parities 1 through 3, whereas WTLOSS in ADSG sows was greater $(P<0.05)$ in Parity 4.

Wean-to-service interval after weaning their first litter for GPK347 sows (11.2 d) and DK sows (12.8 d) were less $(P<0.05)$ than for all other genetic lines (Table 11). However, because conception rate at first service was lower for DK sows, only GPK347 sows differed from other lines in farrowing interval (GPK347 = $143.4 \mathrm{~d}$, mean of other lines $=148.2 \mathrm{~d}$ ). In addition, $77.9 \%$ of the GPK347 sows were serviced within $10 \mathrm{~d}$ of weaning their first litter compared with 63.7 to $71.3 \%$ for other lines.

Wean-to-service intervals were less at Parity 2 than Parity 1 , and no line differences $(P>0.05)$ were observed. However, farrowing interval differences among lines fell into two classes, with the GPK347, DK, and NSR sows having farrowing intervals between 141.4 and $142.8 \mathrm{~d}$, whereas other lines ranged from 143.8 to $144.4 \mathrm{~d}$. The reduction in average wean-to-service interval from first to second litter is consistent with greater LFI $(P<0.05$; Table 9$)$ and less WTLOSS $(P<$ 0.05; Table 9$)$ during lactation for second-parity sows.

Lines differed $(P<0.05)$ for wean-to-service interval following weaning of the third-parity litter, although the means were similar to those for Parity 2. The GPK347 line had numerically the lowest average (8.5 d) wean-to-service interval, but their mean differed only from the means of $11.4 \mathrm{~d}$ for ADSG sows and $10.1 \mathrm{~d}$ for DB sows. The GPK347 sows continued to have greatest percentage of females expressing estrus within $10 \mathrm{~d}$ postweaning, being $4 \%$ greater than NSR sows and 7 to $9 \%$ greater than other lines.

The GPK347 sows had an unusual combination of performance traits. They were the smallest sows and ate less feed during each lactation period than other sows. They had the greatest absolute weight loss and by far the greatest relative weight loss during lactation. They also had the greatest loss of backfat during lactation. Yet, GPK347 sows had the largest litters at birth, weaned the most pigs, and had the shortest wean-toservice and farrowing intervals. The only traits for which GPK347 sows were not greater than or equal to other lines were litter birth and weaning weights. The GPK347 sows seem to possess a unique combination of genes for enhanced reproductive efficiency that is likely the result of the intensive selection for litter size and ovulation rate practiced in the $\mathrm{NE}$ Index line, from which sires of the GPK347 sows came (Johnson et al., 1999). Lower lactation feed intake has been shown to negatively affect wean-to-conception interval, litter weight at weaning, and subsequent litter size (Koketsu et al., 1996), and greater lactation weight loss has been reported to increase wean-to-estrus interval (Tantasuparuk et al., 2001) in swine. Sterning et al. (1996) reported that as sows increased the amount of weight lost in lactation measured relative to weight on entry to the farrowing facility, there was a concurrent relative increase in percentage of backfat lost relative to backfat at farrowing and a subsequent increase in the interval from weaning to estrus. These findings are in contrast to the performance observed for the GPK347 female line evaluated in the present study.

In contrast to the GPK347 sows, sows of the ADSG and DK lines that had greater $(P<0.05) \mathrm{FW}$, greater $(P<0.05)$ LFI, and less $(P<0.05)$ WTLOSS during lactation, but had longer $(P<0.05)$ wean-to-service intervals. More research into physiological mechanisms that relate FW, BF, BFLOSS, and LFI with wean-toservice interval and subsequent litter sizes and weights is needed, as the present study shows the relationships are not consistent across all genetic lines.

The observed variability in reproductive performance among genetic lines, derived from predominantly the Landrace and Yorkshire breeds and comprised of very similar breed proportions, when housed and managed under standard environmental conditions, indicates that genetic variability exists between the nucleus populations utilized in this study.

\section{Implications}

Genetic differences in reproductive performance among commercial $F_{1}$ females exist and in many cases are very large and would be expected to have large economic effects. Commercial swine producers have many alternatives for sources of stocks. This study provides data for them to choose effectively among the lines evaluated to match genetic resources with production expectations for their farms. The lines used expressed maximum heterosis; thus, the differences in performance were likely due to additive gene action and/or specific combining ability. Results should be used in production models to develop optimal management strategies for sows of each line. Results of the study 
provide a sound basis for comparing maternal performance among the lines. Additional analyses including progeny growth and carcass performance are needed to determine economic differences in enterprises based on sows of each line.

\section{Literature Cited}

Bidanel, J. P., J. Gruand, and C. Legault. 1994. An overview of twenty years of selection for litter size in pigs using "Hyperprolific" schemes. Proc. 5th World Cong. Genet. Appl. Livest. Prod., Guelph, Canada 17:512-515.

Casey, D., T. A. Rathje, and R. K. Johnson. 1994. Second thoughts on selection for components of reproduction in swine. Proc. 5th World Cong. Genet. Appl. Livest. Prod., Guelph, Canada $17: 315-318$

Guedes, R. M. C., and R. H. G. Nogueira. 1996. The influence of parity order and body condition on weaning-to-oestrous interval of sows. Page 593 in Proc. 14th Int. Pig Vet. Soc. Cong., Bologna, Italy.

Kerr, J. C., and N. D. Cameron. 1995. Reproductive performance of pigs selected for components of efficient lean growth. Anim. Sci. 60:281-290.

Koketsu, Y., G. D. Dial, and V. L. King. 1996. Influence of various factors on farrowing rate on farms using early weaning. J. Anim. Sci. 75:2580-2587.

Johnson, R. K., M. K. Nielsen, and D. S. Casey. 1999. Responses in ovulation rate, embryonal survival, and litter traits in swine to 14 generations of selection to increase litter size. J. Anim. Sci. 77:541-557.

Neal, S. M., R. K, Johnson, and R. J. Kittok. 1989. Index selection for components of litter size in swine: Response to five generations of selection. J. Anim. Sci. 67:1939-1945.
NPPC. 1995. Terminal Line Program Results. Natl. Pork Prod. Counc. Des Moines, IA.

NPPC. 2000. Maternal Line Genetic Evaluation Program Design. Pages 45-75 in Maternal Line National Genetic Evaluation Program Results. Des Moines, IA.

NRC. 1998. Pages 110-123 in Nutrient Requirements of Swine. 10th rev. ed. Natl. Acad. Press, Washington, DC.

Roehe, R. 1999. Genetic determination of individual birth weight and its association with sow productivity traits using Bayesian analysis. J. Anim. Sci. 77:330-343.

Rothschild, M. F., and J. P. Bidanel. 1998. Biology and Genetics of Reproduction. Pages 313-344 in the Genetics of the Pig. M. F. Rothschild and A. Ruvinsky, ed. CAB International, New York.

Ruiz-Flores, A., and R. K. Johnson. 2001. Direct and correlated responses to two-stage selection for ovulation rate and number of fully formed pigs at birth in swine. J. Anim. Sci. 79:2286-2297.

See, M. T., J. W. Mabry, J. Venner, T. J. Baas, K. J. Stalder, and S. J. Moeller. 2000. Reproductive progress of American Yorkshire swine. Proc. 14th Int. Cong. Anim. Reprod., Stockholm, Sweden 1:309.(Abstr.)

Stalder, K. J., J. W. Mabry, J. Venner, T. J. Baas, S. J. Moeller, and M. T. See. 2000. Reproductive trait genetic trends in American Landrace swine. Proc. 14th Int. Cong. Anim. Reprod., Stockholm, Sweden 1:305.(Abstr.)

Sterning, M., F. Hulten, S. Einarsson, K. Andersson, and H. Hoist. 1996. Relationships between weight loss during lactation, blood parameters and reproduction traits in primiparous sows. Page 570 in Proc. 14th Int. Pig. Vet. Soc. Cong. Bologna, Italy.

Tantasuparuk, W., A. Dalin, N. Lundeheim, A. Kunavongkrit, S. Einarsson. 2001. Body weight loss during lactation and its influence on weaning-to-service interval and ovulation rate in Landrace and Yorkshire sows in the tropical environment of Thailand. Anim. Reprod. Sci. 65:273-281. 